ORIGINAL ARTICLE

\title{
Association between obstructive lung disease and markers of HIV infection in a high-risk cohort
}

\author{
M Bradley Drummond, ${ }^{1}$ Gregory D Kirk, ${ }^{1,2}$ Jacquie Astemborski, ${ }^{2}$ Mariah M Marshall, ${ }^{2}$ \\ Shruti H Mehta, ${ }^{2}$ John F McDyer, ${ }^{1}$ Robert H Brown, ${ }^{1}$ Robert A Wise, ${ }^{1}$ \\ Christian A Merlo ${ }^{1}$
}

\begin{abstract}
- Additional materials are published online only. To view these files please visit the journal online (http://thorax.bmj. com/content/67/4.toc)

'Department of Medicine, School of Medicine, Johns Hopkins University, Baltimore, Maryland, USA

${ }^{2}$ Department of Epidemiology, Bloomberg School of Public Health, Johns Hopkins University, Baltimore, Maryland, USA
\end{abstract}

\section{Correspondence to} Dr M Bradley Drummond, Division of Pulmonary and Critical Care Medicine, 5501 Hopkins Bayview Circle, JHAAC 4B.70, Baltimore, MD 21224, USA; mdrummo3@jhmi.edu

Received 28 June 2011 Accepted 26 October 2011 Published Online First 16 November 2011

\section{ABSTRACT}

Background Evidence suggests an association between HIV infection and the presence of obstructive lung disease (OLD). However, the associations between specific markers of HIV infection and OLD remain unclear. A study was undertaken to determine the independent associations of HIV infection, CD4 cell count and plasma HIV viral load with the presence of OLD in an urban cohort. Methods Clinical, laboratory and spirometric data from the AIDS Linked to the Intravenous Experience (ALIVE) study, an observational study of current and former injection drug users in Baltimore, Maryland, were analysed. Multivariable logistic regression models were generated to identify HIV infection indices independently associated with OLD.

Results Of 1077 participants (mean \pm SD age $48 \pm 8$ years), $89 \%$ were African-American, $65 \%$ were men and $86 \%$ were current smokers. A total of $303(28 \%)$ were HIV infected and 176 (16\%) had spirometry-defined OLD. Higher viral load was independently associated with OLD. HIV-infected individuals with viral load $>200000$ copies $/ \mathrm{ml}$ had a 3.4-fold increase in the odds of OLD compared with HIV-negative participants (95\% Cl 1.24 to 9.39; $p=0.02$ ). The association between higher HIV viral load and OLD persisted after accounting for antiretroviral therapy use (OR 4.06, 95\% Cl 1.41 to $11.7 ; p=0.01$ ). No association was observed between HIV serostatus or CD4 cell count and the presence of OLD.

Conclusion In a cohort at risk for OLD and HIV infection, high viral load but not CD4 cell count was associated with an increased prevalence of spirometry-defined OLD. These findings suggest that higher viral load may contribute mechanistically to the increased risk of OLD in patients with HIV infection.

\section{INTRODUCTION}

Obstructive lung disease (OLD), including asthma and chronic obstructive pulmonary disease (COPD), is associated with substantial morbidity and mortality in the USA. ${ }^{12}$ Risk factors for the development of OLD, such as tobacco use and low socioeconomic status, are prevalent in individuals at risk or infected with HIV. ${ }^{3}$ There has been an increased awareness of the association between HIV infection and the prevalence of COPD.$^{5-7}$ Diaz and colleagues previously described an accelerated form of radiographic emphysema in HIV-infected smokers. ${ }^{5}$ Crothers and colleagues observed an increased odds of COPD diagnosed via ICD-9 diagnosis or self-report in HIV-infected individuals

\section{Key messages}

What is the key question?

- What is the association between different indices of HIV infection and the presence of obstructive lung disease (OLD)?

\section{What is the bottom line?}

- High viral load, but not CD4 cell count, is independently associated with an increased prevalence of spirometry-defined OLD in an urban high-risk cohort.

\section{Why read on?}

- These findings suggest that the higher viral load may contribute mechanistically to the increased risk of OLD, offering insight into ways to decrease the risk of OLD in at-risk individuals with HIV.

from a Veterans Administration (VA) cohort. $^{6}$ Further analysis of this cohort demonstrated an increased risk of ICD-9 diagnosed COPD, but not asthma, in the combination antiretroviral era. ${ }^{8}$ While reports have described the prevalence and severity of airflow obstruction among HIV-infected individuals, ${ }^{9-11}$ it remains unclear which markers of HIV infection (CD4 cell count, plasma HIV viral load) are associated with spirometry-defined OLD.

The AIDS Linked to the Intravenous Experience (ALIVE) study has prospectively followed a cohort of injection drug users in Baltimore, Maryland since 1988. ${ }^{12}$ Clinical, laboratory and spirometric measurements have been collected longitudinally in this cohort at risk or with HIV infection. We have previously described the unrecognised burden of OLD and respiratory symptoms in this cohort, ${ }^{13}$ but the relationship between HIV infection and OLD was not investigated. The heavy smoking patterns and detailed information on HIV-related characteristics makes this cohort an ideal population in which to examine rigorously the relationship between HIV and OLD. In the current study we use cross-sectional and retrospective longitudinal data from the ALIVE study to determine the independent associations between HIV infection, CD4 count and plasma HIV viral load with prevalent OLD in an urban cohort with heavy tobacco use. We hypothesise that indices of more severe 
HIV infection will be independently associated with an increase in the odds of OLD.

\section{METHODS}

\section{Study cohort}

As described previously, ${ }^{12}$ since 1988 ALIVE has followed participants aged $\geq 18$ years, living in inner city Baltimore, Maryland and with a history of injecting drugs. At biannual visits, participants complete HIV-specific questionnaires and provide blood samples. Since 2007, participants have performed pre-bronchodilator spirometry testing at each study visit. We performed a cross-sectional analysis nested within the ongoing cohort study of all participants undergoing spirometry between 9 January 2007 and 26 June 2009. The study was approved by the Institutional Review Board of Johns Hopkins University (NA_00020295) and all participants provided written informed consent.

\section{Data collection}

Cross-sectional data was collected on or within 6 months before the first spirometry visit, including demographic, laboratory and clinical data focused on smoking behaviour and respiratory symptoms. Smoking patterns, injection drug use habits and antiretroviral use were determined by self-report. Respiratory infections were identified through self-report and confirmed through medical records. Pre-bronchodilator spirometry was performed using KoKo pneumotachs (Pulmonary Data Services, Louisville, Colorado, USA) in accordance with American Thoracic Society guidelines. ${ }^{14}$ Percentage predicted values were calculated using standard formulae. ${ }^{15}$ The post-bronchodilator response was defined according to published guidelines. ${ }^{16}$ Separate analyses were performed defining OLD using two criteria: (1) ratio of the forced expiratory volume in $1 \mathrm{~s}\left(\mathrm{FEV}_{1}\right)$ to forced vital capacity (FVC) of $\leq 70 \%{ }^{17}$; and (2) $\mathrm{FEV}_{1} / \mathrm{FVC}$ less than the predicted lower limit of normal (LLN). ${ }^{15}$ Analyses using fixed ratio criteria are presented here while analyses using LLN criteria are presented in the online supplement. We abstracted retrospective longitudinal CD4 and viral load data from prior ALIVE visits for additional modelling of HIV indices described below.

\section{Statistical analysis}

Clinical and demographic characteristics between groups were compared using the $t$ test for normally distributed continuous variables and the Wilcoxon rank sum test for skewed data. All data are presented as mean (SD) for normally distributed data and median (IOR) for non-normally distributed data. Categorical variables were compared with Pearson $\chi^{2}$ and Fisher exact tests. A $p$ value $\leq 0.05$ was used to infer statistical significance.

Logistic regression models were generated to explore associations between indices of HIV and the presence of OLD. The primary analysis included cross-sectional CD4 and viral load data from the 6-month window prior to the spirometry (baseline) visit. CD4 cell count was modelled continuously, dichotomously at clinically relevant thresholds (eg, 200, 350 cells $/ \mathrm{mm}^{3}$ ) and in various increments (eg, per 50 cells $/ \mathrm{mm}^{3}$, per 100 cells/ $\mathrm{mm}^{3}$ ). HIV viral load was modelled continuously, dichotomously at different thresholds (eg, 75000 copies $/ \mathrm{ml}, 200000$ copies/ml) and categorically at clinical thresholds ( $<400$ copies/ $\mathrm{ml}$ vs $400-75000$ copies $/ \mathrm{ml}$ vs $>75000$ copies $/ \mathrm{ml}$; $<$ or $>100000$ copies $/ \mathrm{ml}$ ). Because HIV infection is a time-varying covariate, retrospective longitudinal data were used for secondary models (see figure 1). These models included nadir, maximum and time-weighted average (calculated as the area

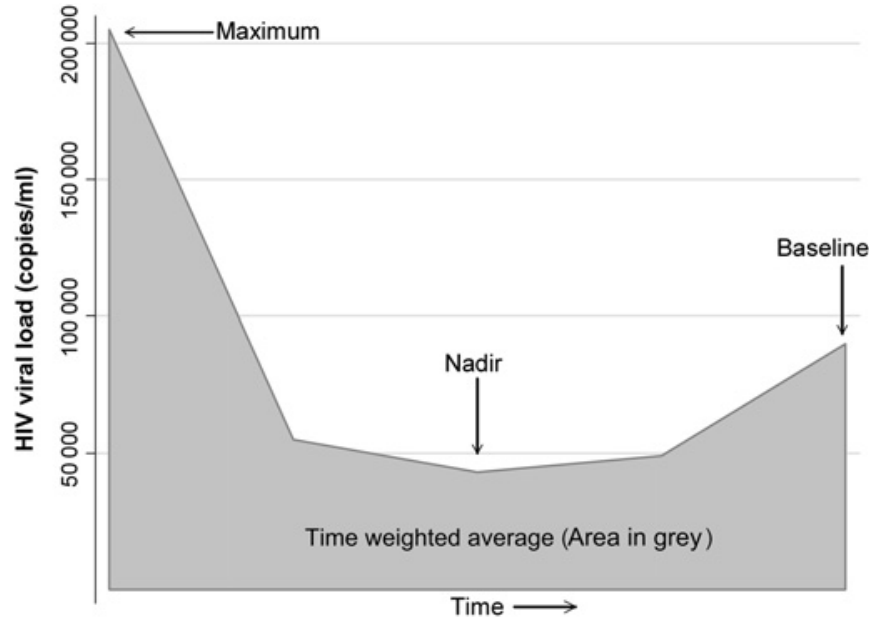

Figure 1 Idealised graph of viral load measurements. For analysis, the baseline HIV CD4 and viral load (obtained at the time of spirometry) were used. Additional measures from retrospective longitudinal data were used to determine the nadir, maximum and time-weighted average (calculated by the area under the curve in grey) over duration of follow-up.

under the curve over follow-up time) CD4 count and HIV viral load. Significant relationships were then assessed with multivariable logistic regression models accounting for demographic and clinical covariates associated with OLD. Smoking history was modelled both continuously and dichotomously. Heavy smoking was defined as $\geq 40$ pack-years, representing the 75 th percentile of the cohort. Covariates were evaluated based upon relevance from clinical literature review and/or exploratory data analyses. Collinearity was assessed by measuring the variance inflation factor. Stata V.10.0 (Stata Corp) was used for statistical analysis.

\section{RESULTS}

\section{Participant characteristics}

Of 1348 ALIVE participants seen during the study period, a total of 1077 participated in the lung sub-study. The median (IOR) duration of follow-up for retrospective parameters was 7.1 (0.6-9.5) years. The characteristics of the participants included in the analysis were similar to those not included, with the exception of viral load which was higher in those not included (median (IOR) 8619 (142-76300) vs 1190 (400-30700). Overall, the mean age of participants was $48 \pm 8$ years, nearly $90 \%$ were of black race, two-thirds were men and $303(28 \%)$ were HIV infected. Of the cohort, $86 \%$ were current smokers and $9 \%$ were former smokers. The mean $\mathrm{FEV}_{1} / \mathrm{FVC}$ ratio of the entire cohort was $0.76 \pm 0.08$, with a mean $\mathrm{FEV}_{1}$ of $92 \pm 18 \%$ predicted. Spirometry-defined obstruction was present in 176 $(16 \%)$ of the entire cohort, with no difference by HIV serostatus. Of these 176 participants with spirometry-defined OLD, 86 (49\%) reported no physician diagnosis of OLD, 13 (7\%) COPD, $47(27 \%)$ asthma, $24(14 \%)$ both asthma and COPD and $6(3 \%)$ had no response. A subset of 30 participants with OLD underwent pre- and post-bronchodilator spirometry to assess for reversible airflow obstruction. Eighteen $(60 \%)$ did not have an acute bronchodilator response while $12(40 \%)$ met ATS criteria for reversibility.

A total of $51(4.7 \%)$ had both HIV and OLD. The median CD4 cell count of HIV-infected participants was 323 cells $/ \mathrm{mm}^{3}$ (IOR 179-491) with $169(56 \%)$ using antiretroviral therapy in the previous 6 months, 143 (47\%) had HIV RNA levels $\leq 400$ copies/ $\mathrm{ml}$ (the lower limit of assay detection) and $79(26 \%)$ ever had 
Table 1 Clinical and demographic characteristics of study participants

\begin{tabular}{|c|c|c|c|}
\hline & OLD absent & OLD present & p Value \\
\hline $\mathrm{N}$ & 901 & 176 & \\
\hline Age, years & $47.7(7.76)$ & $49.6(8.88)$ & 0.004 \\
\hline Male, n (\%) & $586(65)$ & $118(67)$ & 0.61 \\
\hline Black race, n (\%) & $805(89)$ & $149(85)$ & 0.07 \\
\hline $\mathrm{BMI}, \mathrm{kg} / \mathrm{m}^{2}$ & $25.7(22.7-30.1)$ & $23.9(21.5-28.1)$ & $<0.001$ \\
\hline \multicolumn{4}{|l|}{ Smoking status, $\mathrm{n}(\%)$} \\
\hline Current & $769(85)$ & $155(88)$ & 0.55 \\
\hline Former & $84(9)$ & $15(9)$ & \\
\hline Never & $47(5)$ & $6(3)$ & \\
\hline Smoking, pack-years & $20(12-33)$ & $22(14-39)$ & 0.02 \\
\hline \multicolumn{4}{|l|}{$\mathrm{FEV}_{1}$} \\
\hline Absolute (I) & $2.92(0.74)$ & $2.26(0.82)$ & $<0.001$ \\
\hline$\%$ Predicted & $95.7(15.4)$ & $71.7(18.8)$ & $<0.001$ \\
\hline FVC (I) & $3.70(0.96)$ & $3.57(1.15)$ & 0.11 \\
\hline $\mathrm{FEV}_{1} / \mathrm{FVC}$ ratio & $0.79(0.05)$ & $0.63(0.07)$ & $<0.001$ \\
\hline Ever smoked cocaine or heroin, $\mathrm{n}(\%)$ & 643 (72) & $126(72)$ & 0.99 \\
\hline Hepatitis C antibody-positive, n (\%) & $754(84)$ & $149(85)$ & 0.75 \\
\hline \multicolumn{4}{|l|}{ Current IDU, n (\%)* } \\
\hline None & $523(58)$ & $105(60)$ & 0.17 \\
\hline$<1$ injection/day & $221(25)$ & $33(19)$ & \\
\hline$\geq 1$ injection/day & $157(17)$ & $38(22)$ & \\
\hline
\end{tabular}

Values presented as mean (SD) or median (IQR) unless indicated otherwise.

* In previous 6 months.

$\mathrm{BMI}$, body mass index; $\mathrm{FEV}_{1}$, forced expiratory volume in $1 \mathrm{~s}$; FVC, forced vital capacity; IDU, injection drug use; OLD, obstructive lung disease; pack-years, number of packs smoked per day $\times$ years smoked.

a viral load $>200000$ copies/ml during follow-up. Higher viral load was associated with lower CD4 cell count (viral load $<400$ copies/ml: 459 CD4 cells $/ \mathrm{mm}^{3}$; viral load 401-200 000 copies/ $\mathrm{ml}: 302 \mathrm{CD} 4 \mathrm{cells} / \mathrm{mm}^{3}$; viral load $>200000$ copies $/ \mathrm{ml}: 132$ CD4 cells $\left./ \mathrm{mm}^{3} ; \mathrm{p}<0.01\right)$.

When stratifying by OLD status, subjects with OLD were 2 years older, had lower body mass index (BMI) and heavier smoking exposure, but no differences were observed in gender, race, drug use habits or HIV status (table 1). Even fewer differences were observed among HIV-infected participants stratified by OLD status (table 2 ).

\section{Analysis of factors associated with OLD}

In univariate analysis, several clinical and demographic characteristics were associated with OLD including older age, history
Table 2 Characteristics of HIV-infected participants

\begin{tabular}{|c|c|c|c|}
\hline & OLD absent & OLD present & p Value \\
\hline $\mathrm{N}$ & 252 & 51 & 0.79 \\
\hline \multicolumn{4}{|l|}{ CD4 count, n (\%)* } \\
\hline$<100$ cells $/ \mathrm{mm}^{3}$ & $25(10)$ & $5(9)$ & 0.66 \\
\hline $100-199$ cells $/ \mathrm{mm}^{3}$ & $41(16)$ & $11(22)$ & \\
\hline $200-349$ cells $/ \mathrm{mm}^{3}$ & $73(29)$ & $11(22)$ & \\
\hline$>350$ cells $/ \mathrm{mm}^{3}$ & $113(45)$ & $24(47)$ & \\
\hline \multicolumn{4}{|l|}{ CD8 count, n (\%)* } \\
\hline$<500$ cells $/ \mathrm{mm}^{3}$ & $64(25)$ & $10(19)$ & 0.11 \\
\hline $500-1000$ cells $/ \mathrm{mm}^{3}$ & $123(49)$ & $33(65)$ & \\
\hline$>1000$ cells $/ \mathrm{mm}^{3}$ & $65(26)$ & $8(16)$ & \\
\hline \multicolumn{4}{|l|}{ HIV RNA level, n (\%)* } \\
\hline$<400$ copies $/ \mathrm{ml}$ & $118(47)$ & $25(49)$ & 0.02 \\
\hline 400-200 000 copies $/ \mathrm{ml}$ & $123(49)$ & $19(37)$ & \\
\hline$>200000$ copies $/ \mathrm{ml}$ & $11(4)$ & $7(14)$ & \\
\hline HIV RNA $\left(\log _{10} \text { copies } / \mathrm{ml}\right)^{*} \dagger$ & $4.33(3.65-4.76)$ & $4.23(3.18-5.33)$ & 0.91 \\
\hline ART use ever, n (\%)* & $177(70)$ & $33(65)$ & 0.46 \\
\hline ART use in prior 6 months, $\mathrm{n}(\%)^{*}$ & $143(57)$ & $26(51)$ & 0.45 \\
\hline Anti-Pneumocystis therapy, $\mathrm{n}(\%)^{*} \neq$ & $82(32)$ & $19(37)$ & 0.52 \\
\hline \multicolumn{4}{|l|}{ Pneumonia, n (\%) } \\
\hline Bacterial & $93(10)$ & 34 (19) & 0.001 \\
\hline Pneumocystis & $13(1)$ & $3(2)$ & 0.79 \\
\hline
\end{tabular}

of bacterial pneumonia, lower BMI and pack-years smoking (table 3). HIV infection status was not associated with OLD (OR 1.05, 95\% CI 0.74 to $1.50 ; \mathrm{p}=0.786$ ). When modelling baseline HIV RNA levels, there was a non-significant increase in the likelihood of OLD when evaluated continuously (OR 1.26 per 100000 copies $/ \mathrm{ml}, 95 \%$ CI 0.96 to $1.65 ; \mathrm{p}=0.09$ ). There was a significantly increased odds of OLD in the highest viral load group (OR 3.30, 95\% CI 1.26 to 8.69; $\mathrm{p}=0.015$ ) (table 3). There was no association between baseline absolute CD4 count (OR 1.00 per 50 cells $/ \mathrm{mm}^{3}, 95 \%$ CI 0.94 to $1.06 ; \mathrm{p}=0.96$ ). Nadir, maximum and time-weighted averaged CD4 and HIV RNA levels were not associated with OLD (data not shown). The absolute CD8 count and CD4/CD8 ratio were not associated with OLD. There was no association between hepatitis $C$ virus

Table 3 Characteristics associated with OLD in entire cohort

\begin{tabular}{|c|c|c|c|}
\hline Characteristic & $\begin{array}{l}\text { Unadjusted } \\
\text { OR (95\% CI) }\end{array}$ & $\begin{array}{l}\text { Adjusted } \\
\text { OR }(95 \% \mathrm{CI}) *\end{array}$ & p Value $†$ \\
\hline Age (per 10 years) & $1.36(1.10$ to 1.68$)$ & $1.38(1.08$ to 1.76$)$ & 0.01 \\
\hline Black race & $0.66(0.41$ to 1.04$)$ & $0.43(0.25$ to 0.72$)$ & 0.002 \\
\hline \multicolumn{4}{|l|}{ BMI category $\left(\mathrm{kg} / \mathrm{m}^{2}\right)$} \\
\hline$<21$ & Reference & Reference & $<0.01$ \\
\hline $21-27$ & $0.81(0.52$ to 1.28$)$ & $0.80(0.50$ to 1.29$)$ & \\
\hline$>27$ & $0.52(0.31$ to 0.86$)$ & $0.50(0.29$ to 0.85$)$ & \\
\hline Heavy smoking $\ddagger$ & $1.89(1.27$ to 2.80$)$ & $1.62(1.05$ to 2.49$)$ & 0.03 \\
\hline History of bacterial pneumonia & $2.08(1.35$ to 3.20$)$ & 2.07 (1.29 to 3.32$)$ & 0.003 \\
\hline \multicolumn{4}{|l|}{ HIV status } \\
\hline Negative & Reference & Reference & 0.58 \\
\hline Positive, VL $<200000$ copies/ml & 0.95 (0.65 to 1.38$)$ & $0.85(0.56$ to 1.29$)$ & \\
\hline Positive, VL $\geq 200000$ copies/ml & $3.30(1.26$ to 8.69$)$ & 3.41 (1.24 to 9.39$)$ & \\
\hline
\end{tabular}


(HCV) serostatus and OLD (OR 1.08, 95\% CI 0.30 to 3.87; $\mathrm{p}=0.90)$.

After accounting for relevant characteristics identified in univariate analysis, the observed association between higher baseline HIV viral load and OLD persisted (table 3). Compared with HIV-negative participants, HIV-infected individuals with viral load $>200000$ copies $/ \mathrm{ml}$ had a 3.4-fold increase in the odds of OLD (OR 3.41, 95\% CI 1.24 to 9.39; $\mathrm{p}=0.02$ ). Other indices of HIV infection were not associated with an increased odds of OLD in separate models including HIV infection (OR 0.96, 95\% CI 0.65 to $1.42 ; \mathrm{p}=0.84$ ) or baseline CD4 cell count $<200$ cell/ $\mathrm{mm}^{3}$ (OR $1.08,95 \% \mathrm{CI} 0.57$ to 2.04 ). Nadir, maximum and timeweighted average CD4 and HIV viral load levels were not associated with OLD. Selecting the 131 participants with longest follow-up time, we observed a non-significant increase in the odds of OLD in the highest quartile of time-weighted average HIV viral load (OR 1.81, 95\% CI 0.61 to 5.33). Neither exclusion of BMI, incorporating markers of socioeconomic status (high school education, employment in the last 6 months), inclusion of $\mathrm{CD} 4$ or $\mathrm{CD} 8$ measurements, HCV serostatus nor modelling different types and durations of drug use altered the association between HIV viral load and OLD.

Several demographic characteristics remained strong independent factors associated with OLD. Each 10-year increase in age was associated with an approximately $40 \%$ increase in the odds of OLD (OR 1.38, 95\% CI 1.08 to 1.76; $\mathrm{p}=0.01$ ). Black race and highest BMI category were both associated with a reduced odds of OLD (OR $0.43,95 \%$ CI 0.25 to $0.72, p=0.002$ and OR $0.50,95 \%$ CI 0.29 to $0.85, p=0.01$, respectively). Both a history of heavy smoking and a history of bacterial pneumonia were independently associated with the presence of OLD. The smoking effect was present when smoking was modelled categorically ( $\geq 40$ vs $<40$ pack-years) or continuously (per 10 packyears). Similarly, the association between pneumonia and OLD was present when pneumonia was modelled in a categorical $(<1$, $\geq 1$ ) or continuous $(0,1,2,3)$ manner.

To determine the impact of antiretroviral therapy on the association between HIV and OLD, we separately evaluated 303 HIV-infected participants (table 4). Participants with a viral load $>200000$ copies/ml had a fourfold higher likelihood of OLD than those with a viral load $\leq 200000$ copies/ml (OR 4.06, 95\% CI 1.41 to 11.7; $\mathrm{p}=0.01$ ). As observed in the total cohort, black race was associated with lower odds of OLD. Inclusion of CD4 or CD8 measures did not alter the association between HIV viral load and OLD among HIV-infected individuals.
When defining OLD with LLN criteria rather than a fixed ratio definition, nine additional participants met the criteria for OLD. Multivariate models using LLN criteria attenuated the age and race effects in the overall cohort and the race effect in the HIVonly analysis. However, using LLN criteria did not alter the associations between higher HIV viral load and OLD (see tables 1 and 2 in online supplement).

\section{DISCUSSION}

In this study of more than 1000 current and former injection drug users with nearly ubiquitous smoking exposure, we found that high HIV viral load, but not CD4 cell count, was independently associated with an increased odds of spirometrydefined OLD. Specifically, viral load exceeding 200000 copies/ml increased the odds of OLD more than threefold. After accounting for antiretroviral use among HIV-infected participants, high viral load remained independently associated with a fourfold increase in the odds of OLD.

Our observations of the relationship between higher HIV viral load and OLD expand the current understanding of the interaction between HIV infection and the development of OLD. To our knowledge, this is the first report to describe a viral load threshold at which the likelihood of spirometry-defined OLD was increased. Previous studies have described the association between HIV seropositivity and radiographic emphysema or ICD-9/self-reported OLD, but not an association with viral load. ${ }^{5}$ Our analysis revealed similar risk estimates for other predictors of OLD (age, race, bacterial pneumonia, use of antiretroviral therapy) in the VA study. In contrast to the VA cohort, ALIVE represents a community-based cohort with more limited use of antiretroviral therapy and more heterogeneous disease severity not easily captured by HIV serostatus. Our contrasting observations may also be related to differing characteristics of the study populations (male and female injection drug users vs male veterans) and the definition of OLD (spirometry-based vs ICD-9/self-report). The lack of an association between longitudinal measures of viral load may reflect challenges in modelling viral exposure in a cohort with heterogeneous disease severity and differential follow-up.

Despite an association between HIV viral load levels and CD4 cell count, we did not observe an association between CD4 levels and OLD, although our study may have been underpowered to detect such a relationship. In the VA study, increasing CD4 cell count and lower odds of OLD was of borderline significance with ICD-9 diagnosis but was not present when OLD was

Table 4 Characteristics associated with OLD among HIV-infected participants only

\begin{tabular}{|c|c|c|c|}
\hline Characteristic & $\begin{array}{l}\text { Unadjusted } \\
\text { OR (95\% CI) }\end{array}$ & $\begin{array}{l}\text { Adjusted } \\
\text { OR }(95 \% \mathrm{Cl})^{*}\end{array}$ & p Value $\nmid$ \\
\hline Age (per 10 years) & 1.40 (0.87 to 2.23$)$ & $1.40(0.84$ to 2.36$)$ & 0.20 \\
\hline Black race & $0.34(0.12$ to 0.97$)$ & 0.23 (0.07 to 0.73 ) & 0.01 \\
\hline \multicolumn{4}{|l|}{ BMI category $\left(\mathrm{kg} / \mathrm{m}^{2}\right)$} \\
\hline$<21$ & Reference & Reference & 0.30 \\
\hline $21-27$ & $0.68(0.32$ to 1.43$)$ & $0.68(0.30$ to 1.53$)$ & \\
\hline$>27$ & $0.58(0.25$ to 1.37$)$ & $0.60(0.24$ to 1.53$)$ & \\
\hline Heavy smoking $\ddagger$ & $1.56(0.73$ to 3.31$)$ & $1.35(0.60$ to 3.06$)$ & 0.47 \\
\hline History of bacterial pneumonia & $1.71(0.89$ to 3.28$)$ & $1.72(0.85$ to 3.49$)$ & 0.13 \\
\hline Antiretroviral use & $0.78(0.41$ to 1.47$)$ & $0.60(0.29$ to 1.22$)$ & 0.16 \\
\hline $\begin{array}{l}\mathrm{VL} \geq 200000 \text { copies/ml vs VL }<200000 \\
\text { copies/ml }\end{array}$ & 3.49 (1.28 to 9.48$)$ & $4.06(1.41$ to 11.7$)$ & 0.01 \\
\hline
\end{tabular}

${ }^{*}$ Adjusted for other variables in the table as well as current injection drug use and gender.

tp Value for adjusted model.

$\ddagger \geq 40$ pack-years smoking vs $<40$ pack-years smoking

$\mathrm{BMI}$, body mass index; OLD, obstructive lung disease; VL, viral load. 
diagnosed via self-report. Although an association between use of antiretroviral therapy and the presence ${ }^{10}$ and severity ${ }^{9}$ of airflow obstruction has been described, we did not observe similar effects in our analysis.

Several potential biological mechanisms may explain the association between high HIV viral load and increased odds of OLD. Plasma HIV RNA levels are independently correlated with the percentage and activation of CD8 T cells as well as with progression of HIV infection. ${ }^{18} 19$ HIV-infected smokers with radiographic emphysema have an increased percentage of cytotoxic CD8 lymphocytes compared with HIV-infected smokers without emphysema and HIV-negative smokers. ${ }^{5} \mathrm{CD} 8$ alveolitis is also correlated with the presence and severity of airflow obstruction in smokers with OLD. ${ }^{20}$ Although we did not observe an association between peripheral CD8 lymphocyte levels and OLD, the correlation between peripheral and lung CD8 levels has not been extensively examined in the literature. Twigg and colleagues observed a strong correlation between serum viral load, bronchoalveolar lavage viral load and CD8 alveolitis. ${ }^{21}$ The most robust CD8 alveolitis was seen in participants with CD4 cell counts ranging from 200 to 500, suggesting that HIV virus may be acting independently of immune suppression. Moreover, in lung autopsy studies of HIV-infected individuals, areas of histological emphysema have greater numbers of HIV-infected cells than normal lung. ${ }^{22}$ Finally, HIVinfected individuals have increased levels of inflammatory cytokines which have been implicated in the pathogenesis of COPD. ${ }^{23-26}$ Taken together, these data suggest that uncontrolled HIV infection with elevated viral load may increase susceptibility to OLD. Our cross-sectional study cannot determine a causal relationship between higher HIV RNA levels and OLD. There could also be an effect of OLD in increasing CD8 T cell activation ${ }^{27} 28$ and thereby secondarily increasing HIV RNA levels. Irrespective of the direction, this association with a plausible biological mechanism could have substantial clinical implications for HIV-infected persons with OLD.

It is possible that the observed association between higher plasma viral load and OLD represents behavioural rather than biological effects. Individuals with a high viral load in the effective antiretroviral era may represent persons less likely to seek medical care or more likely to engage in higher-risk behaviours which could potentially increase the odds for developing OLD. We adjusted for several measured variables (eg, income, educational level, illicit drug behaviour) that could generate this bias and observed no impact on the observed associations. However, unmeasured confounders, which we are unable to account for, may still potentially exist.

In addition to the association between elevated HIV viral load and OLD, we also observed several negative associations between covariates and OLD. Compared with BMI $<21 \mathrm{~kg} / \mathrm{m}^{2}$, BMI $>27 \mathrm{~kg} / \mathrm{m}^{2}$ was associated with a $50 \%$ reduction in the odds of OLD. Low BMI is a known risk factor for COPD as well as a marker of poor prognosis in COPD. ${ }^{29} 30$ While BMI $<18 \mathrm{~kg} / \mathrm{m}^{2}$ may be a marker of advanced HIV infection or intense drug use in our cohort, we did not observe collinearity between BMI and high viral load. Moreover, excluding BMI from our multivariate models did not affect the relationship between high viral load and OLD. Despite a lack of association in univariate analysis, we observed a strong protective effect of black race on the presence of OLD in multivariate analysis. This effect is consistent with the earlier VA study. ${ }^{6}$ Although reports have described an association between HCV and OLD, ${ }^{31-33}$ we found no association in our cohort with a high HCV prevalence. HCV is a strong surrogate marker for a history of injec- tion drug use, and studies which do not fully account for behavioural differences (eg, smoking) among injection drug users compared with other HIV risk groups may incorrectly associate HCV with OLD.

Besides the cross-sectional nature of our analysis, our study has other limitations. We are unable to fully determine airflow reversibility; a sample with pre-/post-bronchodilator spirometry suggests a mix of reversible and fixed airflow obstruction is present. Nonetheless, use of spirometric criteria to define OLD extends prior self-reported and administrative diagnoses of HIVassociated lung diseases. Participants not included in the lung sub-study had a statistically higher viral load than those included in the analysis. If the prevalence of OLD in those not included is also different, our estimate of the association between OLD and viral load may be biased. The differential follow-up time in this cohort makes accurate estimates of longitudinal viral load exposure difficult. Our population of urban injection drug users may limit the generalisability of our findings, although this homogeneity may decrease the likelihood that unmeasured exposures confound the association between higher viral load and OLD.

In summary, we have observed a strong independent association between high plasma HIV viral load and the presence of OLD among current and former drug users with a heavy burden of smoking. In addition to biological plausibility, this association was robustly observed with numerous subgroup and sensitivity analyses. These findings suggest that the higher viral load associated with uncontrolled HIV infection may contribute mechanistically to the increased risk of OLD reported in previous studies.

Acknowledgements The authors acknowledge the contributions of the study participants and of the ALIVE and SHIELD study staff.

Funding This study was funded in part by grants from the National Institutes of Health (Grants HL090483, DA04334 and DA12568). MBD by a grant from the National Institutes of Health National Heart, Lung and Blood Institute (K23HL103192).

\section{Competing interests None.}

Ethics approval Johns Hopkins Hospital Institutional Review Board (Approval NA_00020295).

Contributors MBD and CAM were responsible for study design, data analysis and interpretation, initial drafting of the article and revisions. MBD takes full responsibility for the integrity of the work as a whole, from inception to published article. MMM, SHM, JFM, RHB and RAW were responsible for study conception and design, data interpretation and critical revisions for important intellectual content. GDK and JA were responsible for study design, data analysis, data interpretation and critical revisions for important intellectual content. All authors gave final approval of the submitted manuscript.

Provenance and peer review Not commissioned; externally peer reviewed.

\section{REFERENCES}

1. Jemal A, Ward E, Hao $Y$, et al. Trends in the leading causes of death in the United States, 1970-2002. JAMA 2005;294:1255-9.

2. Mannino DM, Homa DM, Akinbami LJ, et al. Surveillance for asthma-United States, 1980-1999. MMWR Surveill Summ 2002;51:1-13.

3. Kirk GD, Merlo CA; Lung HIV Study. HIV infection in the etiology of lung cancer: confounding, causality, and consequences. Proc Am Thorac Soc 2011;8 326-32

4. Marshall MM, McCormack MC, Kirk GD. Effect of cigarette smoking on HIV acquisition, progression, and mortality. AIDS Educ Prev 2009;21(Suppl 3):28-39.

5. Diaz PT, King MA, Pacht ER, et al. Increased susceptibility to pulmonary emphysema among HIV-seropositive smokers. Ann Intern Med 2000;132:369-72.

6. Crothers K, Butt AA, Gibert CL, et al. Increased COPD among HIV-positive compared to HIV-negative veterans. Chest 2006;130:1326-33.

7. Diaz PT, Clanton TL, Pacht ER. Emphysema-like pulmonary disease associated with human immunodeficiency virus infection. Ann Intern Med 1992;116:124-8.

8. Crothers K, Huang L, Goulet JL, et al. HIV infection and risk for incident pulmonary diseases in the combination antiretroviral therapy era. Am J Respir Crit Care Med 2011;183:388-95. 
9. George MP, Kannass M, Huang L, et al. Respiratory symptoms and airway obstruction in HIV-infected subjects in the HAART era. PLOS One 2009;4:e6328.

10. Gingo MR, George MP, Kessinger CJ, et al. Pulmonary function abnormalities in HIVinfected patients during the current antiretroviral therapy era. Am J Respir Crit Care Med 2010;182:790-6.

11. Cui 0, Carruthers S, Mclvor A, et al. Effect of smoking on lung function, respiratory symptoms and respiratory diseases amongst HIV-positive subjects: a cross-sectional study. AIDS Res Ther 2010;7:6.

12. Vlahov D. Anthony JC, Munoz A, et al. The ALIVE study, a longitudinal study of HIV1 infection in intravenous drug users: description of methods and characteristics of participants. NIDA Res Monogr 1991;109:75-100.

13. Drummond MB, Kirk GD, Ricketts EP, et al. Cross sectional analysis of respiratory symptoms in an injection drug user cohort: the impact of obstructive lung disease and HIV. BMC Pulm Med 2010;10:27.

14. Miller MR, Hankinson J, Brusasco V, et al. Standardisation of spirometry. Eur Respir J 2005;26:319-38

15. Hankinson JL, Odencrantz JR, Fedan KB. Spirometric reference values from a sample of the general U.S. population. Am J Respir Crit Care Med 1999;159:179-87.

16. Pellegrino R, Viegi G, Brusasco V, et al. Interpretative strategies for lung function tests. Eur Respir J 2005:26:948-68.

17. Gomez FP, Rodriguez-Roisin R. Global Initiative for Chronic Obstructive Lung Disease (GOLD) guidelines for chronic obstructive pulmonary disease. Curr Opin Pulm Med 2002:8:81-6.

18. Orendi JM, Bloem AC, Borleffs JC, et al. Activation and cell cycle antigens in CD4+ and CD8+ T cells correlate with plasma human immunodeficiency virus (HIV-1) RNA level in HIV-1 infection. J Infect Dis 1998:178:1279-87.

19. Froebel KS, Raab GM, D'Alessandro C, et al. A single measurement of CD38CD8 cells in HIV +, long-term surviving injecting drug users distinguishes those who will progress to AIDS from those who will remain stable. Clin Exp Immunol 2000;122:72-8.

20. Saetta M, Di Stefano A, Turato G, et al. CD8+ T-lymphocytes in peripheral airways of smokers with chronic obstructive pulmonary disease. Am J Respir Crit Care Med 1998:157:822-6.
21. Twigg HL, Soliman DM, Day RB, et al. Lymphocytic alveolitis, bronchoalveolar lavage viral load, and outcome in human immunodeficiency virus infection. Am J Respir Crit Care Med 1999;159:1439-44.

22. Yearsley MM, Diaz PT, Knoell D, et al. Correlation of HIV-1 detection and histology in AIDS-associated emphysema. Diagn Mol Pathol 2005;14:48-52.

23. Matsumoto T, Miike T, Nelson RP, et al. Elevated serum levels of IL-8 in patients with HIV infection. Clin Exp Immunol 1993;93:149-51.

24. Lahdevirta J, Maury CP, Teppo AM, et al. Elevated levels of circulating cachectin/ tumor necrosis factor in patients with acquired immunodeficiency syndrome. Am J Med 1988;85:289-91.

25. Barnes PJ. The cytokine network in asthma and chronic obstructive pulmonary disease. J Clin Invest 2008;118:3546-56.

26. Karadag F, Karul AB, Cildag 0 , et al. Biomarkers of systemic inflammation in stable and exacerbation phases of COPD. Lung 2008;186:403-9.

27. Motz GT, Eppert BL, Wesselkamper SC, et al. Chronic cigarette smoke exposure generates pathogenic T cells capable of driving COPD-like disease in Rag2-/- mice. Am J Respir Crit Care Med 2010:181:1223-33.

28. Shirai T, Suda T, Inui N, et al. Correlation between peripheral blood T-cell profiles and clinical and inflammatory parameters in stable COPD. Allergol Int 2010;59:75-82.

29. Harik-Khan RI, Fleg JL, Wise RA. Body mass index and the risk of COPD. Chest 2002;121:370-6.

30. Celli BR, Cote CG, Marin JM, et al. The body-mass index, airflow obstruction, dyspnea, and exercise capacity index in chronic obstructive pulmonary disease. N Engl J Med 2004;350:1005-12.

31. Kanazawa H, Hirata K, Yoshikawa J. Accelerated decline of lung function in COPD patients with chronic hepatitis $C$ virus infection: a preliminary study based on smal numbers of patients. Chest 2003:123:596-9.

32. Kanazawa H, Yoshikawa J. Accelerated decline in lung function and impaired reversibility with salbutamol in asthmatic patients with chronic hepatitis $\mathrm{C}$ virus infection: a 6-year follow-up study. Am J Med 2004;116:749-52.

33. Silva DR, Stifft J, Cheinquer $\mathrm{H}$, et al. Prevalence of hepatitis $\mathrm{C}$ virus infection in patients with COPD. Epidemiol Infect 2010;138:167-73.

\section{Journal club}

\section{Outpatient management of pulmonary embolism}

This multi-national, randomised trial compared outpatient versus inpatient care in patients with acute pulmonary embolism with a low risk of death (severity index category of I or II). Both groups were treated with enoxaparin ( $\geq 5$ days) and oral anticoagulation ( $\geq 90$ days).

One of the 171 outpatients and none of the 168 inpatients had recurrence of venous thromboembolism within 90 days, meeting the non-inferiority criteria $(<4 \%$ between group difference). With respect to secondary outcomes, two outpatients and no inpatients had major bleeding (intramuscular haematomas) within 14 days. There was one death in each group, neither related to the trial. There was no statistically significant difference in use of medical resources between groups. However, the outpatients had non-significantly more home visits for enoxaparin injections.

The limitations of this trial include the fact that it was an open-label trial, although steps were taken to reduce bias. In addition, the enoxaparin regime used was $1 \mathrm{mg} / \mathrm{kg}$ twice a day as opposed to the usual $1.5 \mathrm{mg} / \mathrm{kg}$ every $24 \mathrm{~h}$. This could have affected the venous thromboembolism recurrence rate.

This well-designed study suggests that outpatient treatment of acute pulmonary embolism can be safe, effective and efficient compared with inpatient treatment when the patient group is very carefully selected. However, the occurrence of potentially avoidable major bleeding and recurrence of venous thromboembolism even in this select group are causes for concern. Further studies are required before this treatment can be routinely recommended as standard practice.

- Aujesky D, Roy PM, Verschuren F, et al. Outpatient versus inpatient treatment for patients with acute pulmonary embolism: an international, open-label, randomised, non-inferiority trial. Lancet 2011:378:41-8.

\section{Sheena Barnett}

Correspondence to Sheena Barnett, ST6 Respiratory Medicine, Royal London Hospital, Barts and the London NHS Trust, Whitechapel Road, Whitechapel, London E1 1BB, UK; snovelend@hotmail.com

Provenance and peer review Not commissioned; internally peer reviewed. 